\title{
The functional significance of mantis peering behaviour
}

\author{
KARL KRAL \\ Institute of Zoology, Karl-Franzens University Graz, Universitaetsplatz 2, A-8010 Graz, Austria; e-mail: karl.kral@uni-graz.at
}

Key words. Mantids, Mantis religiosa, Polyspilota, Tenodera aridifolia sinensis, compound eye, spatial vision, binocular cues, motion cues, range estimation, habitat structure

\begin{abstract}
The aim of this review is to explain the functional significance of mantis peering behaviour from an entomological perspective. First the morphological and optical features of the mantis compound eye that are important for spatial vision are described. The possibility that praying-mantises use binocular retinal disparity (stereopsis) and other alternative visual cues for determining distance in prey capture, are discussed. The primary focus of the review is the importance of peering movements for estimating the distance to stationary objects. Here the following aspects are examined: (1) Direct evidence via object manipulation experiments of absolute distance estimation with the aid of self-induced retinal image motion; (2) the mechanism of absolute distance estimation (with the interaction of visual and proprioceptive information); (3) the range of absolute and relative distance estimation; (4) the influence of target object features on distance estimation; and (5) the relationship between peering behaviour and habitat structures, based on results of studies on three species of mantis.
\end{abstract}

\section{INTRODUCTION}

In the course of evolution, most mantis have developed from active hunters that pursue prey to predators that lie in wait to ambush prey. This has been associated with modifications in the visual system and visually-guided behaviour. The compound eyes of most mantis studied, from early nymphs to adults, are relatively large, since vision is of primary importance. They are apposition eyes, which are adapted to vision in daylight. In the apposition eye, each ommatidium is optically isolated from the other ommatidia (approximately 4,000 ommatidia in early nymphs, or 9,000 in adults). This eye morphology serves to increase spatial resolution (Horridge \& Duelli, 1979; Rossel, 1979; Köck, 1992). Consequently, only incident light that is parallel to the longitudinal axis of an ommatidium is perceived by its eight photoreceptor cells. This means that each ommatidium detects only a single image point from the visual surroundings. Each compound eye thus transmits an image consisting of approximately 4,000 to 9,000 image points to the nervous system. Mantises have a round acute zone with high spatial resolution, with inter-ommatidial angles of about $2^{\circ}$ in early nymphs and less than $1^{\circ}$ in adults in the medio-frontal part of the compound eyes (Barros-Pita \& Maldonado, 1970; Maldonado \& Barros-Pita, 1970; Horridge \& Duelli, 1979; Rossel, 1979; Leitinger, 1994). In early nymphs the interommatidial angles are similar in both the medio-frontal and lateral part of the compound eyes. But the ommatidia in the medio-frontal part are already elongated (Leitinger, 1994). The fields of view of the compound eyes can extend as far as $230^{\circ}$ horizontally and $245^{\circ}$ vertically. This includes a forward-looking binocular field (viewed by both eyes simultaneously) with a horizontal extension of about $40^{\circ}$ in early nymphs and up to $70^{\circ}$ in adults (Rossel, 1979; Köck, 1992; Köck et al., 1993; Prete et al., 2011).
Both the acute zone and the relatively large binocular field of the compound eyes permit distance estimation with the aid of binocular triangulation within the small range of distances within which a mantis can capture prey with its raptorial forelegs. (This range of distances comprises a few millimetres for early nymphs and $2.5 \mathrm{~cm}$ for adults in the case of Mantis religiosa and up to $6 \mathrm{~cm}$ for larger adult mantises.) Binocular triangulation was studied by Rossel (1983), who increased the binocular disparity of the image of the prey object on the retinae of both compound eyes by means of base-out prisms, so that the item of prey appeared to be closer than it actually was. The result was that the mantis underestimated the prey distance and executed a strike that did not reach the prey. Triangulation with the aid of disparity is simple in that it does not involve local binocular connections. Rossel (1986) suggests that a mantis determines the horizontal and vertical position of items of prey independently with the left and right eyes. Results of deprivation experiments support this hypothesis (Mathis et al., 1992).

However, mantis stereoscopic vision is a subject of controversy. For instance, extensive experimental data concerning the location of prey in three-dimensional space by adult females of the African mantis Sphodromantis lineola have cast doubt on the retinal disparity hypothesis (Prete \& Mahaffey, 1993; Prete \& McLean, 1996; Gonka et al., 1999; Prete, 1999). It is suggested that if complexes of lobula giant motion detectors (LGMDs) and descending contralateral motion detectors (DCMDs) in each of the two optic lobes are preferentially responsive to prey-like stimuli moving in the acute zone, and there is a threshold frequency of DCMD spikes necessary to elicit a strike, then the presence of a prey-like stimulus moving in the acute zone of the visual field would be sufficient to trigger a strike. Extracellular electrophysiological recordings for both cervical nerve cords have 


\section{Object}

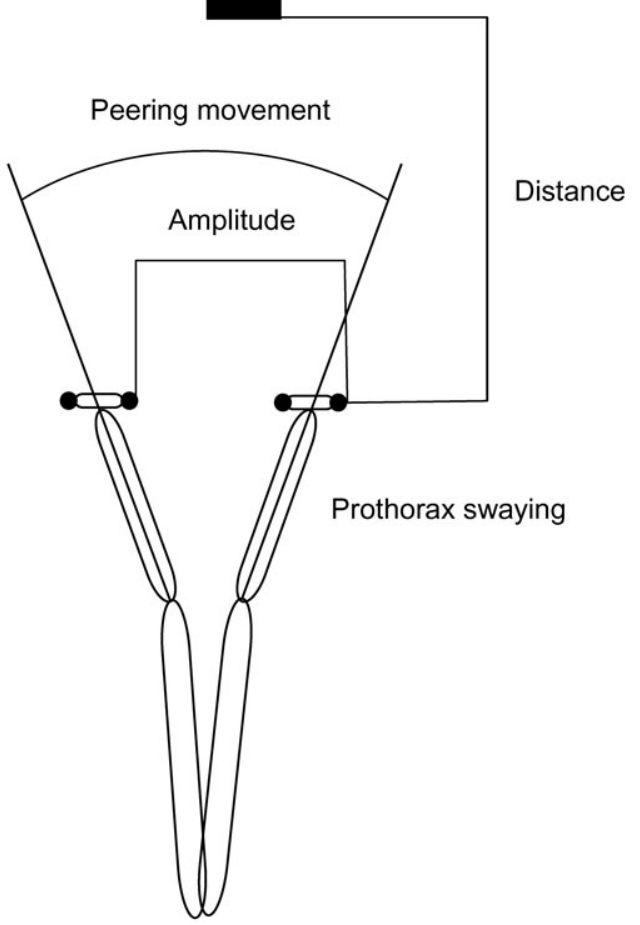

Fig. 1. Schematic drawing showing a side-to-side peering movement used in determining the distance to the vertical contrast boundary of an object. During peering movements the compensatory head movements during the swaying movement of the prothorax ensure that a mantis always looks straight ahead and the head moves linearly. The amplitude of the peering movement is defined as the distance travelled by the head between the starting point and the end point or turning point. The linear movement of the head results in a change in the angle of incidence of the line of vision relative to the contrast boundary. The magnitude of the change (the image motion) depends upon the distance to the contrast boundary.

shown that only a prey-like stimulus in the area viewed by the acute zone could maximally activate a pair of LGMD-DCMD complexes; if their summed activity reaches a threshold level the mantis strikes (Gonka et al., 1999). With the aid of this hypothesis, Prete and his coworkers have suggested that it is not necessary for a praying mantis to calculate binocular disparity to estimate the prey distance.

If an item of prey is just out of reach and is not moving, mantis nymphs and adults exhibit peering behaviour. The otherwise stationary mantis moves its head and upper body from side to side, simultaneously counter-rotating the very mobile head so as to keep the eyes looking straight ahead towards the target object (Fig. 1). They likewise peer when conspecifics, mates or enemies are detected. All mantises perform peering movements before grasping or jumping on to objects, such as twigs or grass stems, when these are stationary or moving only slightly. A lateral shift in the position of the compound eye thus causes a shift in the angular position of the image of the target object on the retina. As early as 1959, Wallace described peering behaviour in nymphs of the desert locust Schistocerca gregaria and discussed its role in range estimation (see also Collett, 1978; Sobel, 1990: Schistocerca americana; Kral, 2008: Chorthippus brunneus). The peering behaviour of a praying-mantis was studied for the first time by Horridge (1986). Although novel and interesting, the findings did not demonstrate a measurable connection between peering movements and distance estimation, due to a lack of standardisation of the stimulus conditions and quantification of the behavioural responses. Quantifiable studies were then undertaken by the present author's working group, taking into account these necessary fundamental conditions (Walcher \& Kral, 1994; Poteser \& Kral, 1995; Poteser et al., 1998; Kral, 1999, 2003, 2012; Kral \& Devetak, 1999; Kral \& Prete, 2004; Hyden \& Kral, 2005; Kral \& Poteser, 2009).

The aim of this review is to explain the functional significance of peering behaviour from an entomological perspective, particularly for entomologists who have had the opportunity to observe this striking behaviour during field studies of mantises, locusts or grasshoppers (Caelifera), but who were unaware of its significance, or interpreted it merely as a type of wind mimicry. As experimental insects, the European mantis Mantis religiosa (Linnaeus, 1758), the Chinese mantis Tenodera aridifolia sinensis Saussure, 1871 and the South African mantis Polyspilota sp. (an undescribed species from Natal, identified by R. Ehrmann; see Ehrmann, 2002, p. 285) have been used. Nymphs and adults of all three species have been studied in the laboratory, and nymphs and adults of M. religiosa have also been studied in the field (western Slovenia; southern and south eastern Styria, southern Burgenland, Austria).

\section{ESTIMATION OF DISTANCE WITH THE AID OF PEERING MOVEMENTS}

\section{Direct evidence of distance estimation}

When a black rectangular object is moved either counter to or in the same direction as the peering movement, early nymphs of T. aridifolia sinensis and Polyspilota sp. jumping towards an object do not jump far enough, or jump too far, respectively (Poteser \& Kral, 1995; Kral \& Poteser, 1997; Kral, 1998a, b). What is the reason for this? In the former case, object motion counter to the peering movement results in increased image motion, which gives a mantis the illusion of a smaller object distance. In the latter case, object motion in the same direction as the peering movement results in reduced image motion, leading to the impression of a greater object distance.

\section{Mechanism of distance estimation}

An insight into the function of peering movements is provided by the altered jumping behaviour of early nymphs in object manipulation experiments. By means of linear or translatory components of the peering movements, the visual system determines the distance range of a stationary object with the aid of retinal image shifting (for further explanation see Fig. 1). The complete 
blinding of one eye or bilateral blinding of the mediofrontal or lateral eye region and photo-ablation of the acute zone of both eyes significantly impairs distance estimation. Mantis so treated has difficulty finding the nearest, most easily accessible perch (Walcher \& Kral, 1994). These experiments show that both compound eyes must be involved in the measuring process. The mediofrontal region of both compound eyes seems to represent a relational system used in evaluating the inter-stimulus interval. Such a mechanism has already been suggested by Rossel (1986) for the estimation of absolute distances within striking range using binocular triangulation. However, this would mean that every target distance corresponds to a certain inter-stimulus interval. In this regard, it should be noted that the inter-ocular distance and the velocity and amplitude of the peering movements are directly proportional, as shown by ontogenetic studies on Polyspilota sp. (Kral \& Poteser, 2009). The increase in inter-ocular distance and the velocity and amplitude of peering movements over the course of ontogeny results in a greater measuring range and measuring accuracy. It should be noted that investigations of post-embryonic eye development in the phasmid Carausius morosus by Meyer-Rochow \& Keskinen (2003) also show a relationship between visual performance and increasing age. The lateral region of mantis compound eyes may play a role in bringing the target object into the frontal visual field and keeping it there during the peering movements (see also Rossel, 1980).

Target-oriented nymphs and adult males of the species examined here can jump about five times their body length and that of adult females, due to their heavier abdomen, is approximately one or two body lengths. Before jumping a mantis normally increases the amplitude of peering movements with increasing distance to the target. In contrast, the peering velocity is generally kept constant, independently of the target distance (see Fig. 2). However, if objects are located beyond the jumping range, peering velocity may also increase with distance, and the velocity and amplitude may then be decreased again for objects that are quite far away. The decrease in peering velocity and amplitude for long distances could be due to decreased motivation for distance estimation. Objects beyond a certain distance are no longer visually significant (Kral \& Poteser, 1997; Kral, 2012). Jumping range results for all stages in the development of a mantis indicate that the absolute distance (the jumping distance) is determined from both the retinal image motion, due to the dependence of image velocity on distance, and the peering movement, which maintains constant image displacement. This mechanism appears to require a comparison of proprioceptive inputs from the neck with visual inputs from the compound eyes (Poteser \& Kral, 1995; Poteser et al., 1998; Kral, 2003; Kral \& Poteser, 2009). The fact that range information exhibits significant inaccuracy when tergocervical and sternocervical hair plate sensilla in the neck are surgically deafferentiated supports this hypothesis.
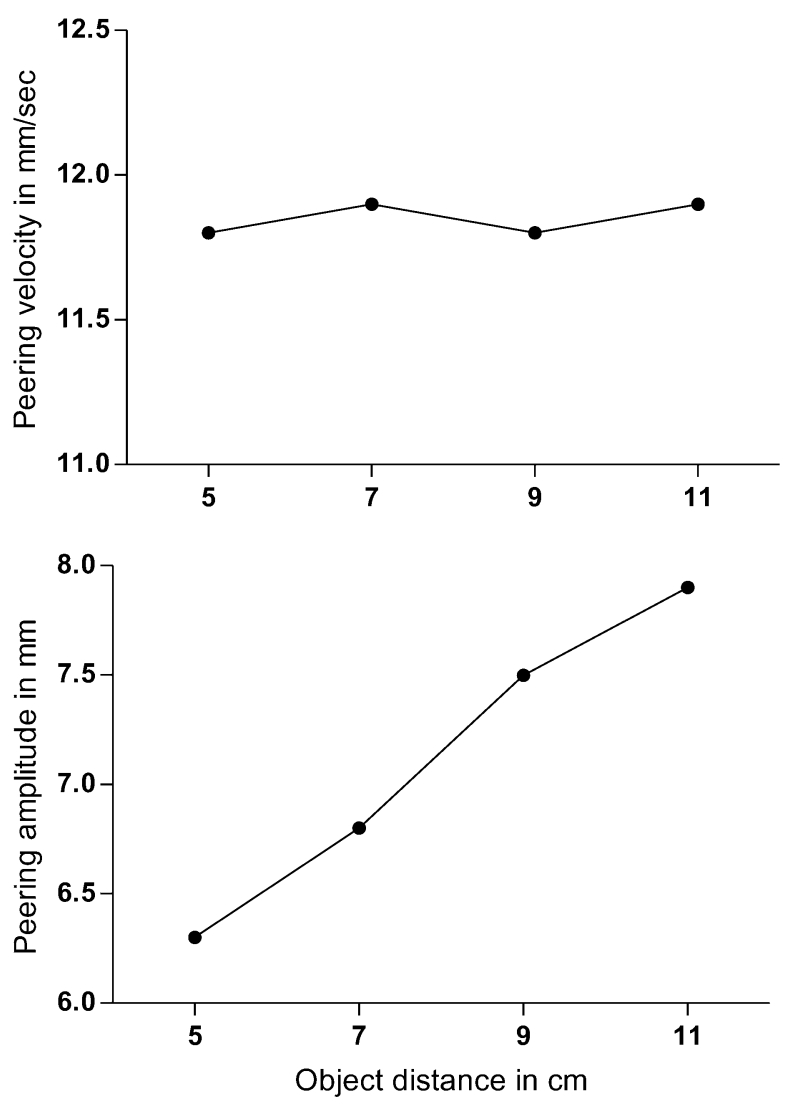

Fig. 2. Diagrams showing how the velocity and maximum amplitude of peering movements executed immediately before a jump are related to the distance to a stationary target object (vertical contrast boundary) within the jump range, using results from a study on a M. religiosa male (K. Kral, unpubl. data).

In contrast, linearization of the peering movement is not affected by impairment of the function of the hair plate sensilla on the neck. Here the compound eyes and/or cervical muscle receptors may play a role. With regard to the compound eyes, any retinal image motion in the lateral visual field during peering should indicate that the head is no longer moving linearly, immediately leading to a correction of the direction of movement by counter-rotation of the head (see also Collett, 1978: locusts). An alternative possibility would be that the target object in the frontal visual field is used as a reference to ensure the linearity of the head movement. The extremely forwarddirected compound eyes of a mantis, with their acute zones, should ensure that any change in the retinal image motion brought about by head rotation is readily detectable.

In addition, inputs from the neck proprioceptors on both sides may also be involved in adjusting the body before a jump. This hypothesis is supported by the fact that unilateral deafferentiation of the tergocervical hair plate sensilla leads to jumps that deviate in the direction of the untreated side (Poteser et al., 1998). The adjustment of the body and head, so that they are precisely aligned, seems to be necessary because, in contrast to locusts and grasshoppers (Cooper, 2006), mantises can only jump straight ahead. They orient their jumps toward 
A

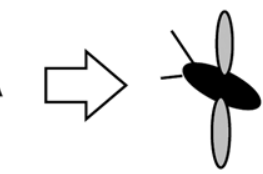

B

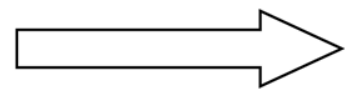

C

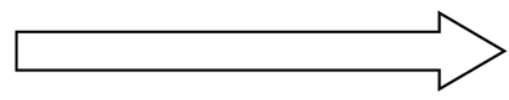

$30 \mathrm{~cm}$

Fig. 3. Schematic diagram showing the range of distances, in the direction of the line of sight, over which $M$. religiosa adults can employ binocular disparity and other binocular cues for prey detection (A) (Rossel, 1986; Kral, 1999; Gonka et al., 1999), and can use self-induced image motion produced by peering movements for estimating absolute distances (B) and relative distances $(\mathrm{C})$ to stationary objects (vertical contrast boundaries) (Kral, 2012).

a vertical edge, so that it is aligned exactly between the two compound eyes. This shows that a mantis prepares for an aimed jump in a significantly more complex way than might be expected. It should also be kept in mind a mantis only jumps, at all stages in its development, if both eyes are functionally fully intact (Walcher \& Kral, 1994; K. Kral, unpubl. observ.).

\section{Range of distance estimation}

Behavioural responses of a mantis, at all stages in its development, such as aimed grasping or aimed jumps immediately following object-oriented peering movements, usually provide clear indications that the mantis has determined the distance to the target object. In the case of an aimed jump, which is largely ballistic in nature, the jump must be preceded by a precise estimate of the distance. However, even if movements are clearly objectrelated, how can a human observer determine whether a mantis performs peering movements for distance measurement, if no behavioural response follows? One indication of the estimation of the distance range of an object in the line of sight could be a high degree of attention of the mantis immediately before and during the object-related peering movements. This can be observed as a mantis rises from a crouching position to an alert upright posture of the prothorax, accompanied by the raising of the abdomen from the ground (K. Kral, unpubl. observ.; Kral, 2012). This alert, attentive behaviour, particularly noticeable in adults, is distinctive and can also be observed when a mantis is in other situations that demand a high degree of attention, for instance during prey detection (Cleal \& Prete, 1996). Another indication of distance estimation, even in the absence of subsequent action, is the close association of peering movements with object dis- tance (Fig. 2); as explained above, increasing the amplitude of peering movements can compensate to a certain extent for the decrease in retinal image displacement with increasing distance.

Recent studies on old nymphs and adults of $M$. religiosa show that absolute distance measurement with the aid of peering is used from the distance range where stereoscopic vision or other binocular cues are effective $(2.5 \mathrm{~cm}$ to $6 \mathrm{~cm})$, up to the range $(10 \mathrm{~cm}$ to $20 \mathrm{~cm})$ where objects are still accessible by means of aimed jumping (see Fig. 3). Behavioural responses and the calculation of retinal image velocity indicate that a mantis can make absolute distance measurements only within this range, but not beyond it (Kral, 2012). (No data are available for young nymphs.) Within this range it can be shown that a mantis is able to detect the nearest object from among several objects, when only a single object is within the frontal visual field. Here the amplitude of the peering movement is decreased so as to narrow the horizontal range of vision as far as possible during scanning. Smallfield forward-looking neurons (found in the higher optical centres of $M$. religiosa and $S$. lineola) detect the small image motions of the respective objects (Berger, 1985; Gonka et al., 1999; Kral \& Prete, 2004). However, this requires a mantis to retain the information concerning object distance until the next object enters the frontal visual field, so as to compare the distance of both objects. Here it should be noted that this type of memory is wellknown for other insects (e.g., Collett, 1992: honeybees). The question is whether a mantis can store information about not only the distance but also the position of the object. On the other hand, it is possible that a mantis simply detects the nearest object (associated with the fastest image motion) and jumps when this object enters the visual field for the second or third time.

For distances of up to $30 \mathrm{~cm}$ or more, old nymphs and adults of M. religiosa seem to be able to use peering for relative range discrimination (Kral, 2012) (Fig. 3). Similar distances for range estimation are reported for adults of the Australian mantis Ciulfina sp. (Hill et al., 2004). This mantis uses peering movements to control its approach to a target object. This is clearly shown when a mantis walks toward a single object located in front of a featureless background; the mantis repeatedly stops to make object-related peering movements in order to check the location of the object (Hill et al., 2004; K. Kral, unpubl. observ.: M. religiosa).

By means of relative distance estimation with the aid of motion parallax, a mantis can also detect objects located in front of a background that is similar with respect to contrast, texture and luminance (for example, a stem of grass in front of several other stems). It achieves this by determining the fastest retinal image motion, independently of the relative motion between the object and background. This permits a mantis to find the nearest of a number of similar objects when these are simultaneously within the visual field. The threshold for figure-ground discrimination can be less than $5 \mathrm{~mm}$ (Poteser \& Kral, 1995). 
To sum up, it should be noted that binocular cues and peering movements, executed perpendicularly to the line of sight, are used to determine the distance to any target object, regardless of the initial position of the object relative to the mantis. This is due to the fact that, unlike other insects, mantises have an exceptionally mobile head that can be turned in any direction, thus permitting alignment of the target object within the frontal visual field of the compound eyes (Horridge, 1986; Rossel, 1996). Once the target is aligned in the frontal visual field, binocular range estimation can then be performed. This differs from the mechanism used by other animals, such as frogs, that are able to use retinal elevation for distance determination, with objects in the lower visual field perceived as being closer than those in the upper visual field (Collett \& Udin, 1988; Collett, 1996). A similar mechanism is proposed for the fiddler crab, an animal that lives on a flat substrate. When a distinct object on the ground comes closer, its retinal image moves downwards to the ventral visual field (Zeil \& Al-Mutairi, 1996). In both cases, the eyes are in a fixed position relative to the ground plane.

\section{Influence of target object features on distance estimation}

Further investigations on $M$. religiosa have shown the importance of strong contrast boundaries for range determination (Hyden \& Kral, 2005). During bright sunny days, mantis nymphs and adults use the high contrast of surrounding structures for active exploration by means of peering movements (K. Kral, unpubl. observ.). When exploring, they prefer long to short contours, and vertical to oblique or curved contours (Hyden \& Kral, 2005). An object is more readily interpreted as a target as the length of its contours increases. It is clear that to a certain extent long contours stimulate more photoreceptor cells that are important for the range measuring process. It is also not surprising that movement stimuli are intensified for vertical contours that are oriented perpendicularly to the peering movements.

\section{Relationship between peering behaviour and habitat structures}

Finally, in light of the findings described above, it seems plausible that in the three species of mantis studied, M. religiosa, T. aridifolia sinensis and Polyspilota, the horizontal component of the peering movements is adapted to range estimation for upright structures prevalent in the environment. The course of movement is highly precise in Polyspilota sp., fairly precise in T. aridifolia sinensis and less precise or even imprecise in $M$. religiosa (Fig. 4). This applies to nymphs as well as adults. However, all of these three relatively large species of mantis (females, body length approximately $60 \mathrm{~mm}$ to $80 \mathrm{~mm}$; length of hind legs approximately $50 \mathrm{~mm}$ to $70 \mathrm{~mm}$ ) perform similarly pronounced peering movements. Amplitudes can be approximately $16 \mathrm{~mm}$ and velocities approximately $12 \mathrm{~mm} / \mathrm{s}$ in Polyspilota sp. females, as compared with amplitudes of approximately $10 \mathrm{~mm}$ and velocities of approximately $14 \mathrm{~mm} / \mathrm{sec}$ in $M$. religiosa females. The values obtained for $T$. aridifolia

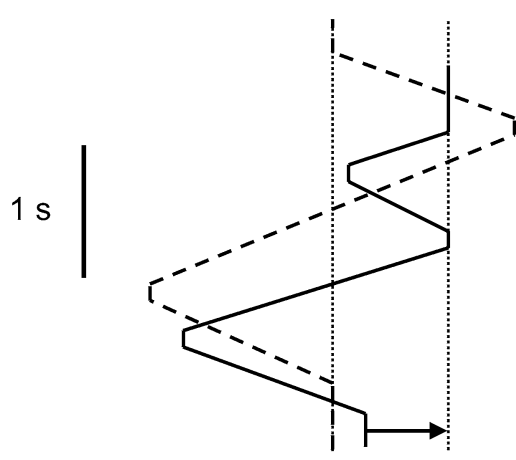

$5 \mathrm{~mm}$

Fig. 4. Schematic diagram showing the translational movement of the head during object-related peering behaviour in a Polyspilota sp. female (broken line) and M. religiosa female (solid line). Movement amplitude is indicated on the x-axis and elapsed time on the y-axis. The distance of the target object (vertical contrast boundary) is $10 \mathrm{~cm}$. In Polyspilota the head position and line of sight are the same at the beginning and end of the translational movement. In M. religiosa there is a slight discrepancy (shown by arrow). During the translational movement Polyspilota always looks straight ahead, while in $M$. religiosa the head alignment can vary by a few degrees (not shown) (K. Kral, unpubl. observ.).

sinensis females are intermediate between those found for the other two species (Poteser, 1998; Kral \& Poteser, 2009; Kral, 2012). The differences in the precision of peering movements among the three species could be due to different structural features of their habitats, associated with differing requirements in terms of visual orientation during goal-directed locomotion. There are differences in their habitats. For instance, Polyspilota inhabits highly structured scrub land, preferring bushes and trees (Poteser, 1995; Moira van Staaden, pers. commun.), whereas $M$. religiosa prefers open meadows with somewhat taller grasses (Kral \& Devetak, 1999; K. Kral, pers. observ.). In contrast, $T$. aridifolia sinensis seems to be more of a habitat generalist than the other two species and can persist at a given location for many years as grassland changes to an early stage of forest growth (Rathet \& Hurd, 1983; F.R. Prete, pers. commun.). Unfortunately, there are few experimental studies on the natural history and ecology of mantises. What little information exists is derived from studies on a few temperate zone species, such as $M$. religiosa, T. aridifolia sinensis, the narrowwinged mantis $T$. angustipennis, the Mediterranean mantis Iris oratoria and the Carolina mantis Stagmomantis carolina (e.g. Kaltenbach, 1963; Bartley, 1982; Maxwell \& Eitan, 1998; Kral \& Devetak, 1999; Hurd, 1999; Harris \& Moran, 2000). However, the Mediterranean ground mantis Ameles decolor, also found in Istria (Croatia) (K. Kral, pers. observ.), is largely unstudied. Almost nothing is known of the great majority of prayingmantis that live in subtropical and tropical regions. The highest density of species is found in the savannahs and forests of Africa and in rainforests of Southeast Asia (Ehrmann, 2002). 


\section{CONCLUSIONS}

Based on the results of behavioural, morphological and physiological investigations and additional information from the literature, it can be concluded that in all stages in the development of a mantis the primary role of peering behaviour is to enable an otherwise motionless insect to estimate the distance to stationary objects. Absolute range estimation with the aid of self-induced retinal image motion (image velocity) and information from neck proprioceptors permits a mantis to make controlled goaloriented movements such as grasping a twig, avoiding obstacles, or jumping to a perch. The capability of performing relative range estimation with the aid of motion parallax allows a mantis to explore its immediate surroundings. Figure-ground discrimination permits them to navigate within a structured environment. Both types of cues can help a mantis to minimise or avoid random, unnecessary movements, which may be noticed by predators or prey. Thus, peering behaviour allows a mantis to carry out efficient, inconspicuous foraging for prey, and locomotion for purposes of mating or finding a resting place, while minimising the risk of predation. However, the significance of and demands on peering behaviour also depend upon the (animate and inanimate) characteristics of specific habitats. There are thus still many unanswered questions.

ACKNOWLEDGEMENTS. I would like to thank M. Ansell (Halifax, Canada) for correcting the English text. The research was supported financially by grants from the Austrian Science Foundation to K. Kral. Special thanks are due to my former students A.-K. Jakobs, A. Köck, F. Walcher, M. Poteser, G. Leitinger and $\mathrm{K}$. Hyden.

\section{REFERENCES}

Barros-Pita J.C. \& Maldonado H. 1970: A fovea in the praying mantis eye. II. Some morphological characteristics. $Z$. Vergl. Physiol. 67: 79-92.

BARTLEY J.A. 1982: Movement patterns in adult male and female mantids, Tenodera aridifolia sinensis Saussure (Orthoptera: Mantodea). Environ. Entomol. 11: 1108-1111.

Berger F.A. 1985: Morphologie und Physiologie einiger visueller Interneuronen in den optischen Ganglien der Gottesanbeterin Mantis religiosa. Doctoral thesis, University of Düsseldorf.

Cleal K. \& Prete F.R. 1996: The predatory strike of free ranging praying mantises, Sphodromantis lineola (Burr.). II. Strikes in the horizontal plane. Brain Behav. Evol. 48: 191-204.

Collett T.S. 1978: Peering - a locust behaviour pattern for obtaining motion parallax information. J. Exp. Biol. 76: 237-241.

Collett T.S. 1992: Landmark learning and guidance in insects. Phil. Trans. R. Soc. Lond. (B) 337: 295-303.

Collett T.S. 1996: Vision: Simple stereopsis. Curr. Biol. 6: $1392-1395$.

Collett T.S. \& Udin S.B. 1988: Frogs use retinal elevation as a cue to distance. J. Comp. Physiol. (A) 163: 677-683.

COOPER W.E. 2006: Risk factors and escape strategy in the grasshopper Dissosteira carolina. Behaviour 143: 1201-1218.

Ehrmann R. 2002: Mantodea, Gottesanbeterinnen der Welt. Natur und Tier, Münster, 519 pp.
Gonka M.D., Laurie T.J. \& Prete F.R. 1999: Responses of movement sensitive descending visual interneurons to preylike stimuli in the praying mantis, Sphodromantis lineola (Burmeister). Brain Behav. Evol. 54: 243-262.

HARRIS S.J. \& MORAN M.D. 2000: Life history and population characteristics of the mantid Stagmomantis carolina (Mantodea: Mantidae). Popul. Ecol. 29: 64-68.

Hill P.J.B., Holwell G.I., Göth A. \& Herberstein M.E. 2004: Preference for habitats with low structural complexity in the praying mantid Ciulfina sp. (Mantidae). Acta Oecol. 26: 1-7.

Horridge G.A. 1986: A theory of insect vision: velocity parallax. Proc. R. Soc. Lond. (B) 229: 13-27.

Horridge G.A. \& Duelli P. 1979: Anatomy of the regional differences in the eye of the mantis Ciulfina. J. Exp. Biol. 80: 165-190.

HURD L.E. 1999: Ecology of praying mantids. In Prete F.R., Wells H., Wells P.H. \& Hurd L.E. (eds): The Praying Mantids: Research Perspectives. Johns Hopkins University Press, Baltimore, MD, pp. 43-60.

HydEN K. \& KRAL K. 2005: The role of edges in the selection of a jump target in Mantis religiosa. Behav. Process. 70: $122-131$.

KaltenBaCh A. 1963: Kritische Untersuchungen zur Systematik, Biologie und Verbreitung der europäischen Fangheuschrecken (Dictyoptera - Mantidae). Zool. Jb. Syst. 90: 521-598.

KöcK A. 1992: Morphologische und optische Indizien für eine postembryonale Entwicklung des binokularen Mechanismus der Entfernungsmessung bei der Gottesanbeterin Tenodera sinensis. Diploma thesis, University of Graz.

KöcK A., JAKOBS A.-K. \& KRAL K. 1993: Visual prey discrimination in monocular and binocular praying mantis Tenodera sinensis during postembryonic development. J. Insect Physiol. 39: 485-491.

Kral K. 1998a: Spatial vision in the course of an insect's life. Brain, Behav. Evol. 52: 1-6.

Kral K. 1998b: Side-to-side movements to obtain motion depth cues: A short review of research on the praying mantis. Behav. Process. 43: 71-77.

KRAL K. 1999: Binocular vision and distance estimation. In Prete F.R., Wells H., Wells P.H. \& Hurd L.E. (eds): The Praying Mantids: Research Perspectives. Johns Hopkins University Press, Baltimore, MA, pp. 114-140.

KRAL K. 2003: Behavioural-analytical studies of the role of head movements in depth perception in insects, birds and mammals. Behav. Process. 64: 1-12.

KRAL K. 2008: Spatial vision in binocular and monocular common field grasshoppers (Chorthippus brunneus). Physiol. Entomol. 33: 233-237.

KRAL K. 2012: How far stationary contrast boundaries can be away to elicit behavioral responses in praying mantis. $J$. Insect Behav. 25: 127-136.

Kral K. \& Devetak D. 1999: The visual orientation strategies of Mantis religiosa and Empusa fasciata reflect differences in the structure of their visual surroundings. J. Insect Behav. 12: 737-752.

Kral K. \& Poteser M. 1997: Motion parallax as a source of distance information in locusts and mantids. J. Insect Behav. 10: 145-163.

Kral K. \& Poteser M. 2009: Relationship between body size and spatial vision in the praying mantis - An ontogenetic study. J. Orthopt. Res. 18: 153-158.

KrAL K. \& Prete F.R. 2004: In the mind of a hunter: The visual world of praying mantis. In Prete F.R. (ed.): Complex Worlds from Simpler Nervous Systems. MIT Press, Cambridge, MA, pp. 75-115. 
LEITINGER G. 1994: Frühe postembryonale Entwicklung des Komplexanges und der Lamina ganglionaris der Gottesanbeterin nach Photodegeneration der akuten Zone mit Sulforhodamin. Diploma thesis, University of Graz.

Maldonado H. \& Barros-Pita J.C. 1970: A fovea in the praying mantis eye. I. Estimation of the catching distance. $Z$. Vergl. Physiol. 68: 60-71.

Mathis U., Eschbach S. \& Rossel S. 1992: Functional binocular vision is not dependent on visual experience in the praying mantis. Vis. Neurosci. 9: 199-203.

Maxwell M.R. \& Eitan O. 1998: Range expansion of an introduced mantid Iris oratoria and niche overlap with a native mantid Stagmomantis limbata (Mantodea: Mantidae). Ann. Entomol. Soc. Am. 91: 422-429.

Meyer-Rochow V.B. \& Keskinen E. 2003: Post-embryonic photoreceptor development and dark-light adaptation in the stick insect Carausius morosus (Phasmida, Phasmatidae). Appl. Entomol. Zool. 38: 281-291.

Poteser M. 1995: Die Rolle der Eigenbewegung der Gottesanbeterin Polyspilota sp. bei der Entfernungsmessung zu stationären Objekten im Verlauf der postembryonalen Entwicklung. Diploma thesis, University of Graz.

Poteser M. 1998: Die Bedeutung der Bewegungsparallaxe für die räumliche Orientierung von Insekten am Beispiel der Gottesanbeterin Tenodera sinensis. Doctoral thesis, University of Graz.

Poteser M. \& Kral K. 1995: Visual distance discrimination in praying mantis larvae: An index of the use of motion parallax. J. Exp. Biol. 198: 2127-2137.

Poteser M., Pabst M.-A. \& Kral K. 1998: Proprioceptive contribution to distance estimation by motion parallax in a praying mantid. J. Exp. Biol. 201: 1483-1491.

Prete F.R. 1999: Prey recognition. In Prete F.R., Wells H., Wells P.H. \& Hurd L.E. (eds): The Praying Mantids: Research Perspectives. Johns Hopkins University Press, Baltimore, MA, pp. 141-179.
Prete F.R. \& Mahaffey R.J. 1993: Appetitive responses to computer-generated visual stimuli by the praying mantis Sphodromantis lineola (Burm.) Vis. Neurosci. 10: 669-679.

Prete F.R. \& McLean T. 1996: Responses to moving smallfield stimuli by the praying mantis, Sphodromantis lineola (Burmeister). Brain Behav. Evol. 47: 42-54.

Prete F.R., Komito J.L., Dominguez S., Svenson G., López L.Y., Guillen A. \& Bogdanivich N. 2011: Visual stimuli that elicit appetitive behaviors in three morphologically distinct species of praying mantis. J. Comp. Physiol. (A) 197: 877-894.

Rathet I.H. \& HuRd L.E. 1983: Relationships of three cooccurring mantids, Tenodera sinensis (Saussure), T. angustipennis (Saussure), and Mantis religiosa (Linneaus). Am. Midl. Natur. 110: 240-248.

Rossel S. 1979: Regional differences in photoreceptor performance in the eye of the praying mantis. J. Comp. Physiol. 131: 95-112.

Rossel S. 1980: Foveal fixation and tracking in the praying mantis. J. Comp. Physiol. 139: 307-331.

Rossel S. 1983: Binocular stereopsis in an insect. Nature 302: 821-822.

Rossel S. 1986: Binocular spatial localization in the praying mantis. J. Exp. Biol. 120: 265-281.

Rossel S. 1996: Binocular vision in insects: How mantids solve the correspondence problem. Proc. Natl. Acad. Sci. USA 93: $13229-13232$.

Sobel E.C. 1990: The locust's use of motion parallax to measure distance. J. Comp. Physiol. (A) 167: 579-588.

WALChER F. \& Kral K. 1994: Visual deprivation and distance estimation in the praying mantis larvae. Physiol. Entomol. 19: 230-240.

WALLACE G. K. 1959: Visual scanning in the desert locust Schistocerca gregaria. J. Exp. Biol. 36: 512-525.

Zeil J. \& Al-MutaiRi M.M. 1996: The variation of resolution and of ommatidial dimensions in the compound eyes of the fiddler crab Uca lacteal annulipes (Ocypodidae, Brachyura, Decapoda). J. Exp. Biol. 199: 1569-1577.

Received January 12, 2012; revised and accepted February 14, 2012 